\title{
Mangrove species discrimination and health assessment using AVIRIS-NG hyperspectral data
}

\author{
Nilima R. Chaube ${ }^{1, *}$, Nikhil Lele ${ }^{1}$, Arundhati Misra ${ }^{1}$, T. V. R. Murthy ${ }^{1}$, \\ Sudip Manna ${ }^{2}$, Sugata Hazra ${ }^{3}$, Muktipada Panda ${ }^{4}$ and R. N. Samal ${ }^{4}$ \\ ${ }^{1}$ Space Applications Centre, Ahmedabad 380 015, India \\ ${ }^{2}$ Department of Physics, Presidency University, Kolkata 700 073, India \\ ${ }^{3}$ School of Oceanographic Studies, Jadavpur University, Kolkata 700 032, India \\ ${ }^{4}$ Chilika Development Authority, Bhubaneshwar 751014 , India
}

\begin{abstract}
Mangroves play a major role in supporting biodiversity, providing economic and ecological security to the coastal communities, mitigating the effects of climate change and global warming. Species level classification of mangrove forest, understanding physical as well as chemical properties of mangrove vegetation, mangrove health, pigments, and levels of stress are some of the key issues for making scientific and management decisions. Hyperspectral remote sensing owing to its narrow bands, yield information on structural details and canopy parameters. Hyperspectral data over Sundarban and Bhitarkanika mangrove forests are analyzed for species discrimination and forest health assessment. In all, 15 mangrove species in Sundarban and 7 mangrove species in Bhitarkanika have been identified and classified using Spectral Angle Mapper technique. In-situ spectro-radiometer data has been used along with AVIRIS-NG hyperspectral data. Based on response of vegetation in blue, red and near-infrared regions, combination of vegetation indices are used to assess mangrove forest's health. Reduction in NIR reflectance with shift towards lower wavelength has been observed in less healthy groups.
\end{abstract}

Keywords: Coastal forest management, health assessment, hyperspectral data, mangrove species.

\section{Introduction}

MANGROVES are unique forest ecosystems spanning the tropical and subtropical coasts. These forests are of ecological as well as socio-economic importance due to their significant ecosystem services ${ }^{1}$. Mangroves perform a vital ecological role providing habitat for a wide variety of species. Odum et $a{ }^{2}{ }^{2}$ reported over 200 species of fishes are dependent on mangrove habitats during their breeding season. Juvenile fishes prefer mangrove root zone. Apart from fishes, many other reptiles and bird species in the coastal or intertidal regions often forage

*For correspondence. (e-mail: chaube@sac.isro.gov.in) mangrove habitats for breeding, roosting and other activities. Additionally, many species, though not permanent mangrove inhabitants, make use of these areas for foraging, roosting, breeding and other activities. Apart from biological significance, mangroves are known to offer significant protection through shoreline stabilization. Pop-root structure and branching of mangrove canopy reduce the effect of strong winds and strong waves, and protect shorelines even in extreme cases such as tsunamis.

Valiela et $a .^{3}{ }^{3}$ have reported that mangroves are degrading at a rate of $2.1 \%$ annually, which is more threatening than the loss of tropical rain forests. These forests have potential threat from anthropogenic activities and climate change ${ }^{4}$, and need to be preserved. With reference to Indian mangroves, some of the areas are located close to coastal metropolitan cities like Mumbai, Kolkata, Surat and Bhubaneswar, leading to tremendous pressure on this fragile ecosystem. Many mangrove areas are being converted to aquaculture for rearing of prawns, crabs and fishes in artificially created tanks. Such practices have led to deforestation and degradation of mangrove habitats by means of anthropogenic interventions. In order to conserve these habitats, the base knowledge of their spatial distribution under different bioclimatic conditions is essential. Owing to the diverse heterogeneity of mangroves, spatial zonation of species assemblages is still coarsely delineated. Mangrove species discrimination is important to study biotic components of the mangrove ecosystem; the presence of particular species reflects the underlying biology of the ecosystem. Fine-resolution hyperspectral remote sensing is helpful to monitor the inaccessible mangrove forests 5 .

Hyperspectral imagery is acquired using imaging spectrometry, the simultaneous acquisition of images in many narrow (band width less than $10 \mathrm{~nm}$ ) and contiguous spectral bands. As band widths are narrow, local/subtle variations in absorption features can be precisely detected. Moreover, the broad spectral bands in multispectral scanner provide gross information over hundreds 
of nanometres, that falls short of highlighting the finer absorption and reflectance features which are key to species-level discrimination of a forest ecosystem. Mangrove stands of different species composition are hard to distinguish in conventional, moderate spatial resolution, and multi-spectral satellite images ${ }^{6-8}$; this is possible using hyperspectral images from airborne sensors ${ }^{9-12}$. Hyperspectral scanners mostly cover the $400-2500 \mathrm{~nm}$ spectral region, enabling the availability of continuous spectrum compared with multispectral scanners. This increases the possibility of determining the characteristic spectral features for analysis, classification and monitoring of cover types and processes ${ }^{13}$.

The potential of hyperspectral imaging and image processing has already been demonstrated for numerous applications in vegetation structure, composition and physiology, which is mainly driven by its ability to measure reflectance and absorption in specific and narrow spectralbands ${ }^{14-16}$.

Several trials have been made using multispectral observations for species-level classification ${ }^{17}$. Yet, it is difficult to identify boundaries between vegetation communities. In a coastal wetland environment like mangroves, classification becomes complex due to background mixing of spectra from water, soil, wet soil, herbaceous vegetation, emergent vegetation, etc. However, hyperspectral narrow spectral channels offer potential to detect and map spatial heterogeneity in vegetation ${ }^{18-20}$. Various methods have been applied to map mangrove vegetation including spectral angle mapper (SAM), ${ }^{9,21}$, maximum likelihood $^{10,11,14}$, spectral unmixing ${ }^{22}$ and object-based image analysis $^{23}$. All the methods have certain advantages and requirements from field data, and are also subjected to diversity of species and separability issues amongst species.

Asia has the largest mangrove cover followed by Africa, and North and Central America ${ }^{8}$. India is at the 11th position considering global mangrove cover. The Forest Survey of India has reported the mangrove cover of the country as $4628 \mathrm{sq} . \mathrm{km}$. About 55 mangrove species belonging to 22 genera and 18 families are found in India ${ }^{24}$.

In ISRO-NASA AVIRIS-NG airborne campaign in situ ground-truth field measurements were preplanned to develop a hyperspectral library of various mangrove species, analyse in situ spectral signatures for discriminating and mapping mangrove vegetation, species-level classification of mangrove forest and analysing mangrove health characteristics from spectral indices. In this article, mangrove species discrimination and health assessment are presented using hyperspectral data for Sundarbans and Bhitarkanika mangroves of West Bengal and Odisha respectivaly.

\section{Study area and data used}

In India, West Bengal and Odisha are among the pristine mangrove areas. As part of the hyperspectral campaign, dense mangrove habitats were selected for exploring potential of hyperspectral data over these areas. The Sundarbans, a UNESCO World Heritage site, is the largest mangrove region in India, while a Bhitarkanika, Ramsar wetland, is India's second largest mangrove region. These mangrove-rich sites were selected after considering the possibility of in situ data measurement.

Site 1-Lothian island and surroundings: A Wildlife Sanctuary of Sundarbans Biosphere in South 24 Parganas, West Bengal, located between $88^{\circ} 10^{\prime} 6.165^{\prime \prime}-$ $88^{\circ} 21^{\prime} 22.938^{\prime \prime} \mathrm{E}$ and $21^{\circ} 49^{\prime} 57.106^{\prime \prime}-21^{\circ} 32^{\prime} 47.45^{\prime \prime} \mathrm{N}$. Figure 1 shows the study site which consists of Bhagbatpur, a portion of Lothian and Henry islands. The site is imaged in three airstrips.

Site 2 -Bhitarkanika National Park situated in the lower reaches of the Dhamra-Patsala-Maipura River, this is an important mangrove ecosystem along the east coast of India. The National Park comes under Rajnagar Division, Kendrapada district, Odisha, and is located between $20.51^{\circ}-20.85^{\circ} \mathrm{N}$ and $86.75^{\circ}-87.2^{\circ} \mathrm{E}$. The estuaries at the mouth of the rivers Brahmani, Baitarani and Dhamra, and a large number of ramifying creeks, channels and distributaries have given rise to luxuriant growth of mangroves. The study site consists of a large, continuous patch of mangrove forest at Dangmal and Kalibhajdiya islands.

Figure $2 a$ shows the mangrove area in one flight line of AVIRIS-NG, which consists of Bhagbatpur, covered in $5 \mathrm{~km}$ swath of AVIRIS-NG data. Figure $2 b$ shows the Bhitarkanika mangroves imaged in four airstrips during the campaign.

\section{In situ data}

Concurrent to flight schedule, in situ data collection was carried out at both the sites. The data include collection of in situ spectra using handheld spectroradiometer, and field-level water-vapour and ozone values using handheld sunphotometer and ozonometer respectively. Mangrove-related in situ measurements include phytosociological survey by laying $20 \mathrm{~m} \times 20 \mathrm{~m}$ sample plots and recording assemblage type and morphological parameters of mangroves. Additionally, vegetation morphological conditions and signs of degradation were recorded. Soil and leaf samples from mangroves were collected and examined for soil salinity, nutrients and leaf biochemical composition analysis.

\section{Image processing and analysis}

AVIRIS-NG airborne data were processed in order to setup a study area mosaic of three strips of Sunderabans and six strips of Bhitarkanika mangroves. Hyperspectral imaging measures reflectance in contiguous narrowbands which are sensitive to the combined effects of foliage 
chlorophyll concentration, canopy leaf area, foliage clumping and canopy architecture ${ }^{25,26}$. Datasets were first subjected to data dimensionality reduction for the redundancy in data, which improves the processing time.

In situ spectroradiometer data were analysed for similarity and dissimilarity among dominant mangrove species, that were subsequently used in classification of airborne data. $D$-matrix given by Price $^{27}$ was used for finding similarity among species.

$$
D=\left[\frac{1}{\lambda_{b}-\lambda_{a}} \int_{\lambda_{b}}^{\lambda_{a}}\left[S_{1}(\lambda)-S_{2}(\lambda)\right]^{2}\right]^{1 / 2} .
$$

SAM method was used for classification of mangrove ecosystems, which compares image spectra to reference

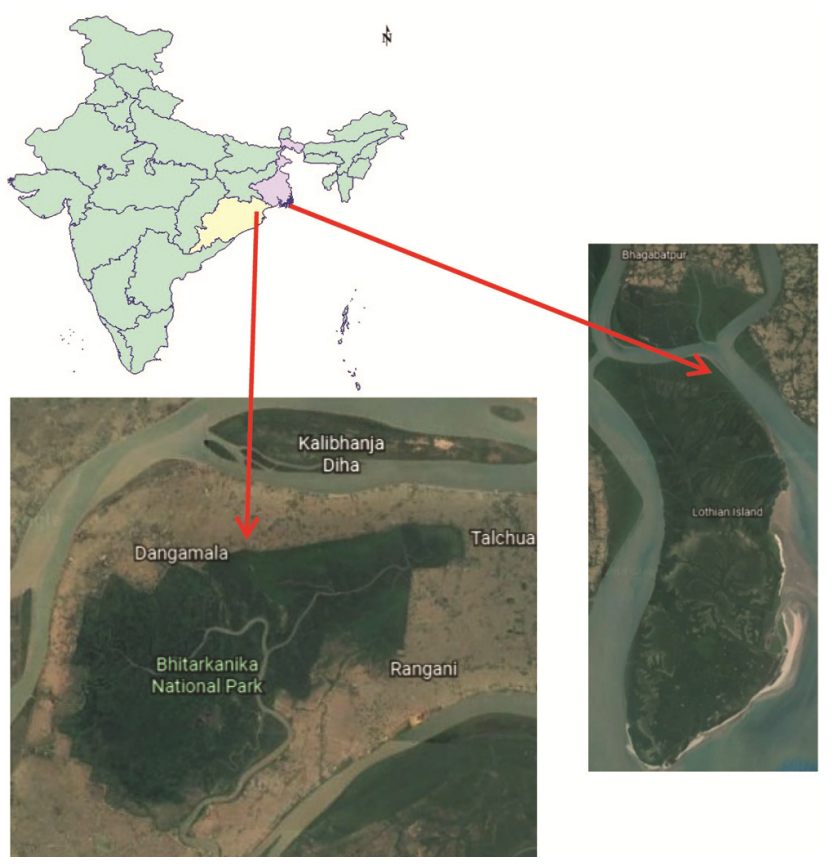

Figure 1. Study areas.

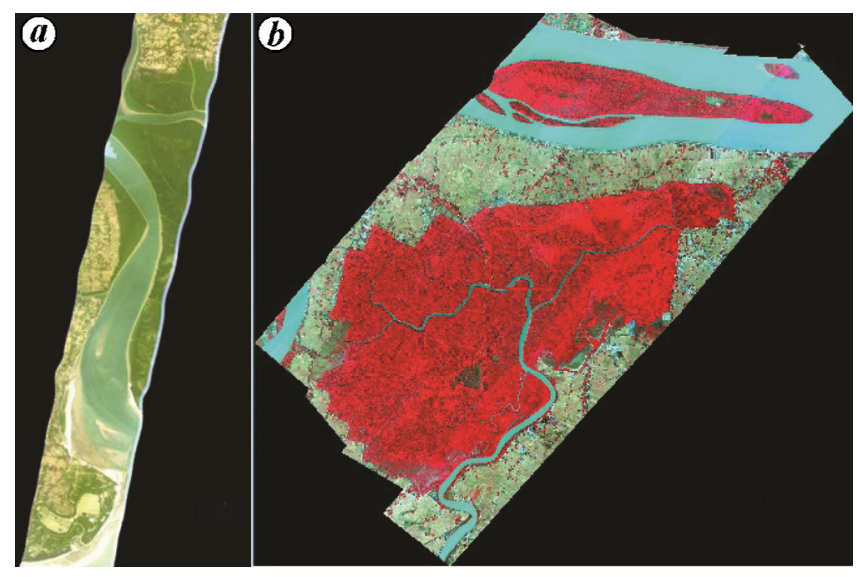

Figure 2. The AVIRIS-NG images: $\boldsymbol{a}$, part of Indian Sundarbans mangrove forest natural colour composite (NCC), West Bengal. $\boldsymbol{b}$, part of Bhitarkanika mangrove forest false colour composite (FCC), Odisha. or end-member spectra. The reference spectra were collected in the field using a spectrometer during groundtruth field campaign. SAM uses the image and referenced spectra as $n$ dimensional vectors, where $n$ is the number of bands in the hyperspectral measurements, and estimates the spectral angle between them considering vector direction and not vector length. The SAM-classified image shows a best match of image and reference spectra at each pixel.

Vegetation analysis involves study of red-edge characteristics of various species, and ultimately vegetation health. Vegetation/canopy greenness is typically considered as one of the indicators for vegetation health. A deviation change in plant health or presence of stress is always reflected in the vegetation canopy, typically in terms of changes in leaf colour (yellowing/wilting of leaves), leaf shedding, etc. Vegetation health is considered here as a combined response from vegetation canopy in terms of structure and function, i.e. greenness index (to evaluate gaps in vegetation), leaf pigment index (as a measure of pigments) and light use efficiency (to estimate plant function). Vegetation greenness was evaluated using enhanced vegetation index (EVI), while carotenoids reflectance index showing changes in leaf total carotenoid concentration relative to chlorophyll concentration and functional aspects were evaluated by applying structure insensitive pigment index (SIPI), which considers the ratio of bulk carotenoids to chlorophyll while decreasing sensitivity to variation in canopy structure. SIPI has been widely used for deriving vegetation stress detection and yield analysis, since it is based on 680 and $800 \mathrm{~nm}-$ the spectral region responsible for providing the necessary quantum energy for photosynthesis reaction. Responses from various spectral regions which are sensitive to canopy structure, canopy pigments and canopy physiological function were combined to derive vegetation health index and displayed using min-max function.

Atmospheric parameters were recorded using sunphotometer and ozonometer during imaging, which are required to process reflectance image from radiance image. Spectroradiometer data of each species were collected at various geolocations. Figure 3 shows a flow chart of the methodology.

\section{Results and discussion}

Various mangrove species were identified and geotagged along with their hyperspectral signatures using a spectroradiometer during ground-truth campaign. Table 1 provides the names of various mangrove species observed during Ground Truth (GT) for Sundarbans and Bhitarkanika.

\section{Analysis of in situ spectra}

Analysis of in situ spectra provided a clue for knowing a priori which species were separable from each other 
before classification. $D$-matrix given by Price $^{27}$ was used for finding similarity among species. The $D$-matrix is useful for analysing feasibility of class separability in data. Based on the relative numbers in the matrix, it can be inferred if two or more species are separable from each other or not. This was evaluated using the method described in Price ${ }^{27}$, that considers response from each species in each spectral channel and its adjacent wavelength, indicated as $\lambda_{\mathrm{a}}$ and $\lambda_{\mathrm{b}}$, while $S_{1}$ and $S_{2}$ indicate two species or classes in the data. Higher the value in $D$ matrix, better is the separability. Table 2 shows $D$-matrix values indicating separability of one species from the other at Bhitarkanika.

Table 1. Mangrove species in Sundarbans, West Bengal and Bhitarkanika, Odisha
Botanical name

Avicennia alba, Blume. (AA)

Aegiceras corniculatum, Blanco. (AC)

Avicennia marina, Forsk. (AM)

Avicennia officinalis, Lamk. (AO)

Aegialitis rotundifolia, Roxb. (AR)

Bruguiera gymnorrhiza, Lamk. (BG)

Bruguiera cylindrica, Blume. (BC)

Heritiera fomes, Buch.-Ham. (HF)

Ceriops decandra, Ding Hou. (CD)

Excoecaria agallocha, Lamk. (EA)

Phoenix paludosa, Roxb. (PP)

Casuarina equisetifolia (CA)

Sonneratia apetala, Buch. Ham. (SA)

Sonneratia caseolaris, Engler. (SC)

Xylocarpus mekongensis, Pierre. (XM)

Bruguiera parviflora Roxb. Wight \& Arn. (BP)

Kandelia candel (L.) Druce (KC)

Rhizophora mucronata Lam. (RM)

Suaeda monoica Forssk (SM)

Xylocarpus granatum K D Koenil (XG)
Local name (Bengali)

Kala bani

Kholsi

Peyara bani

Jaat bani

Tora

Kankra

Bakul kankra

Sundari

Jaat goran

Genwa

Hental

Jau

Keora

Chak keora

Dhundhul

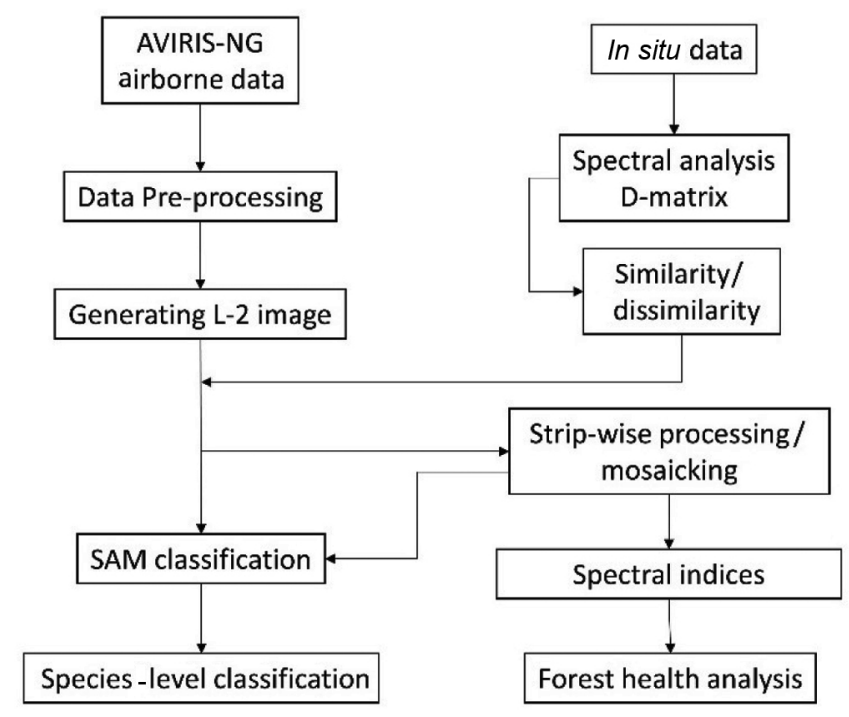

Figure 3. Flow chart showing details of methodology.
The spectra collected during ground truth for each mangrove species were averaged to lower the effect of noise and correlated for different species and wavelengths separately. Figure 4 is graphical representation of correlation for various mangrove species with each other, where each pixel stands for a correlation value which is coded in different colours for the range $0.9-1$. The mangrove species were taken in the order $\mathrm{AA}, \mathrm{AC}, \mathrm{AM}, \mathrm{AO}$, $\mathrm{AR}, \mathrm{BC}, \mathrm{BG}, \mathrm{CD}, \mathrm{CA}, \mathrm{EA}, \mathrm{HF}, \mathrm{PP}, \mathrm{SA}, \mathrm{SC}$ and $\mathrm{XM}$ in rows as well as columns. The diagonal pixels represent the auto-correlation of each species. Figure 5 is a graphical representation of the correlation among different wavelengths for selecting appropriate bands for mangrove species discrimination. In Figure 5 each pixel represents a wavelength, and wavelengths are taken in ascending order across the rows and columns. The sensitive wavelengths $400-1300,1500-1800$ and $2000-2500 \mathrm{~nm}$ were taken for processing based on this correlation analysis.

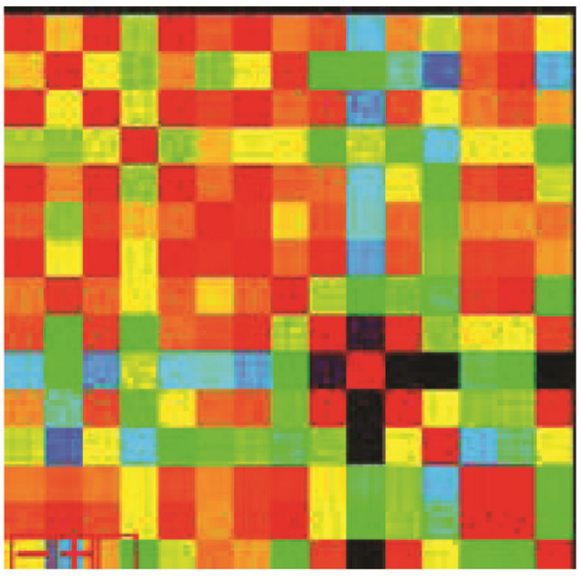

AA

AC

AM

AO

AR

BC

BG

CD

CA

EA

HF

PP

SA

SC

$\mathrm{XM}$

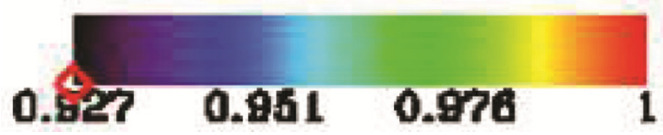

Figure 4. Species correlation : species separability.

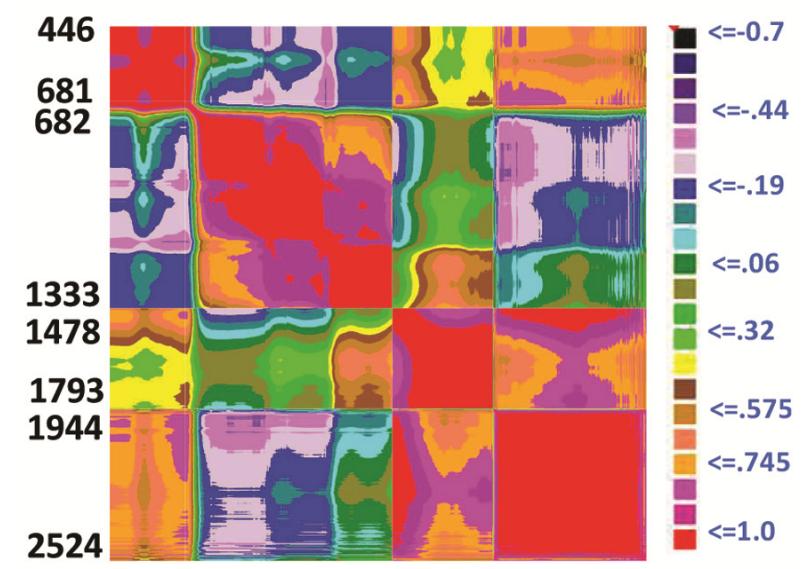

Figure 5. Wavelength correlation : wavelength sensitivity. 
Table 2. Spectral separability analysis using D-matrix. Species with higher difference in the values are better separable in the spectral domain

\begin{tabular}{|c|c|c|c|c|c|c|c|c|c|c|c|c|}
\hline$D$-Matrix & & $\mathrm{AM}$ & $\mathrm{AO}$ & EA & $\mathrm{HF}$ & $\mathrm{RM}$ & SM & $\mathrm{CD}$ & $\mathrm{BP}$ & HF-EA & $\mathrm{KC}$ & $X G$ \\
\hline & AM & & & & & & & & & & & \\
\hline & $\mathrm{AO}$ & 0.058 & & & & & & & & & & \\
\hline & EA & 0.033 & 0.045 & & & & & & & & & \\
\hline & $\mathrm{HF}$ & 0.045 & 0.082 & 0.039 & & & & & & & & \\
\hline & $\mathrm{RM}$ & 0.110 & 0.054 & 0.098 & 0.136 & & & & & & & \\
\hline & SM & 0.117 & 0.062 & 0.103 & 0.139 & 0.019 & & & & & & \\
\hline & $\mathrm{CD}$ & 0.093 & 0.149 & 0.121 & 0.106 & 0.196 & 0.203 & & & & & \\
\hline & BP & 0.051 & 0.027 & 0.049 & 0.082 & 0.064 & 0.069 & 0.135 & & & & \\
\hline & HF-EA & 0.068 & 0.060 & 0.041 & 0.057 & 0.100 & 0.098 & 0.151 & 0.065 & & & \\
\hline & $\mathrm{KC}$ & 0.025 & 0.035 & 0.028 & 0.059 & 0.086 & 0.094 & 0.115 & 0.033 & 0.062 & & \\
\hline & $X G$ & 0.033 & 0.038 & 0.013 & 0.047 & 0.091 & 0.096 & 0.124 & 0.043 & 0.045 & 0.023 & \\
\hline Minimum & & 0.025 & 0.027 & 0.013 & 0.047 & 0.019 & 0.069 & 0.115 & 0.033 & 0.045 & 0.023 & \\
\hline Maximum & & 0.117 & 0.149 & 0.121 & 0.139 & 0.196 & 0.203 & 0.151 & 0.065 & 0.062 & 0.023 & \\
\hline
\end{tabular}

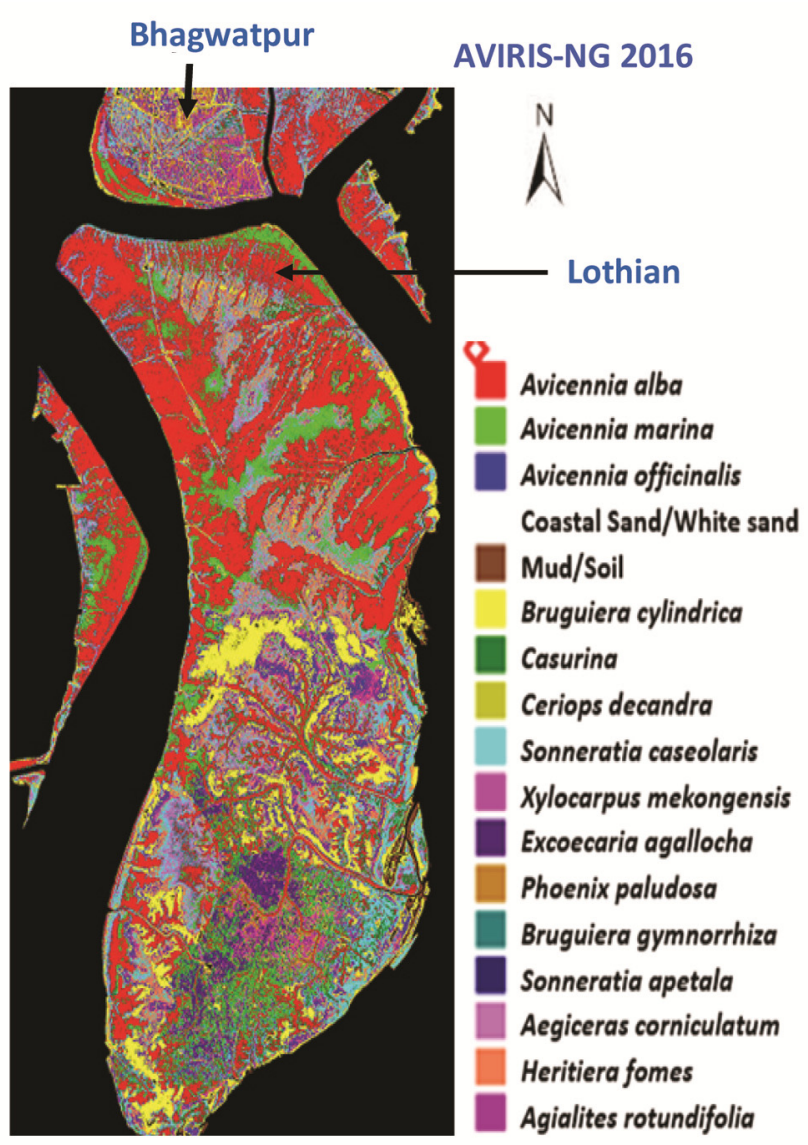

Figure 6. Dominant species discrimination in Sundarbans mangrove.

\section{Species discrimination using spectral angle mapper}

SAM classification is chosen due to its insensitivity to illumination artefacts as different airstrips show variations in illumination. The end-member spectra collected during ground-truth measurement were used to develop a mangrove spectral library. SAM is a supervised classifi- cation which compares the angle between each image pixel vector and library/end-member spectra vector in $n-$ $D$ space. This determines the similarity between two spectra by calculating the angle between the spectra and treating them as vectors in a space with dimensionality equal to the number of wavelength bands. Figures 6 and 7 show the SAM classified images of Sundarbans (mosaic of three flight lines out of six) and Bhitarkanika (mosaic of two flight lines out of six).

Mangroves ecosystems are a complex mosaic of creeks, inundated water, vegetation, understorey, open mudflats, etc. High-resolution remote sensing is an efficient tool to monitor the area as accessibility of such areas is difficult. Some of the dominant land features such as water, mud, coastal sand, dry mudflats, etc. are also visible in Figure 6. In Sundarbans, mostly Avicennia alba and Avicennia marina occupy the water to land transition compared to other mangrove species. Kholshi or Aegiceras corniculatum exists in different elevation and inundation conditions, but not in abundance.

In Bhitarkanika mangroves, dominant species such as A. alba, A. officinalis, A. marina, Excoecaria agallocha and Heritiera fomes were mapped. Certain parts of Bhitarkanika have grasslands which are clearly discriminated using hyperspectral data. Post-classification accuracy of vegetation map was found to be $84.5 \%$, with overall kappa statistics observed to be 0.78 .

\section{Mangrove forest health assessment}

Forest health assessment was done for various species based on EVI and SIPI that make use of 440, 680 and $800 \mathrm{~nm}$. Health assessment was done in two ways:

(1) Difference in vegetation reflectance in red and NIR wavelengths. Qualitative health condition of the same species under similar densities showed pronounced differences (higher the reflectance, better the health). 


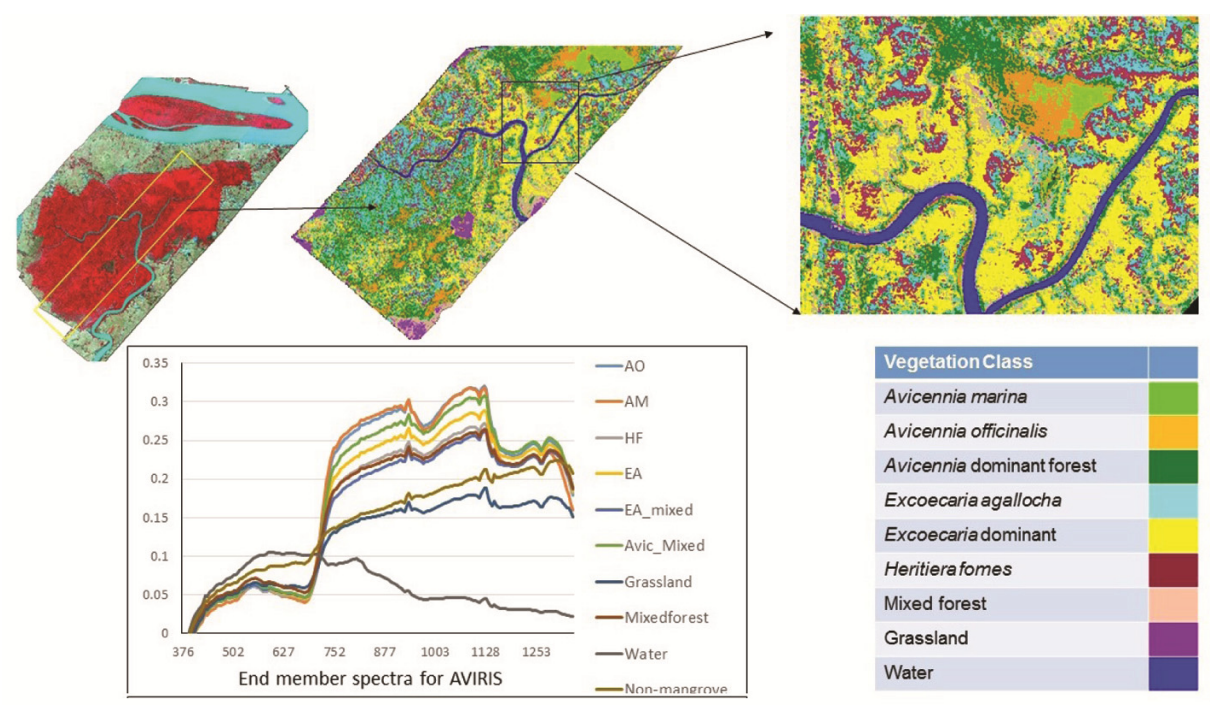

Figure 7. Mangrove forest dominant species discrimination based on spectral angle.
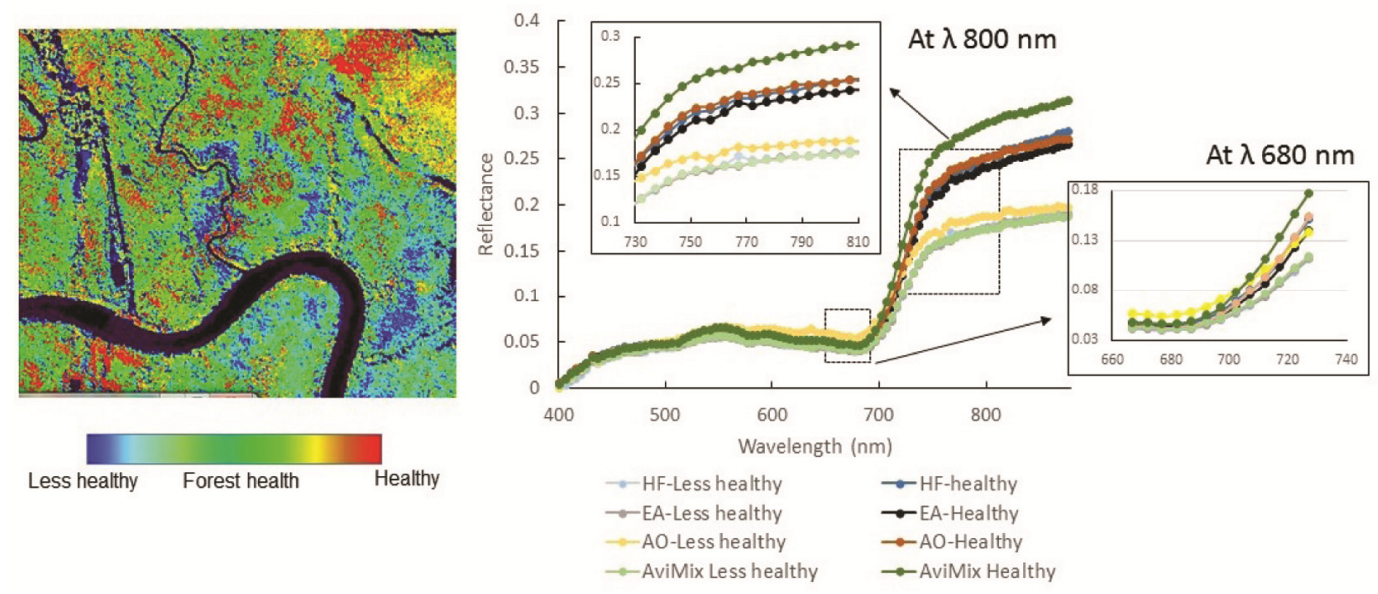

Figure 8. Mangrove forest health assessment.

(2) Red-edge position: In stress-affected less healthy plants, chlorophyll absorption was affected, which is seen in the vegetation spectra, particularly in the red-edge position. Lower values of red edge were found in stressed (less healthy) vegetation (Figure 8).

Excoecaria agallocha: 714 and $729 \mathrm{~nm}$; mixed forest: 714 and $719 \mathrm{~nm}$.

Avicennia mixed forest: 719 and $724 \mathrm{~nm}$ (as less healthy and healthy respectively).

Also, areas close to creeks and jetties as well as along walkways were found to have less healthy vegetation (Figure 8).

\section{Conclusion}

The study highlights application of airborne hyperspectral data for analysing vegetation health based on spectral indices from various spectral channels including red, near-infrared and shortwave infrared regions, and classifying mangrove species by AVIRIS-NG data with $\pm 5 \mathrm{~m}$ accuracy using SAM classification. Airborne hyperspectral data are highly useful for mangrove wetland discrimination and analysing finer vegetation details owing to better spectral and spatial resolution. An automatic strategy can be put in place using periodic hyperspectral data with fine resolution to monitor and manage the mangrove forests, which are generally risky and inaccessible due to the wildlife around them.

1. Huxham, M., Dencer-Brown, A., Diele, K., Kathiresan, K., Nagelkerken, I. and Wanjiru, C., Mangroves and people: local ecosystem services in a changing climate. In Mangrove Ecosystems: A Global Biogeographic Perspective, Springer, Cham, Switzerland, 2017, pp. 245-274.

2. Odum, J. C, Mclvor, C. C. and Smith, T. J., The ecology of mangroves of South Florida: a community profile, US Fish and Wildlife Service/Office of Biological Services, FWS/OBS 81/24, 
January 1982, pp. 1-156; http://www.nwrc.usgs.gov/techrpt/8124.pdf

3. Valiela, I., Bowen, J. L. and York, J. K., Mangrove forests: one of the world's threatened major tropical environments. BioScience, 2001, 51, 807-815.

4. Gilman, E. L., Ellison, J., Duke, N. C. and Field, C., Threats to mangroves from climate change and adaptation options: a review. Aquat. Bot., 2008, 89(2), 237-250.

5. Vaiphasa, C., Ongsomwang, S., Vaiphasa, T. and Skidmore, A K., Tropical mangrove species discrimination using hyperspectral data: a laboratory study. Estuarine, Coast. Shelf Sci., 2005, 65(1-2), 371-379.

6. Green, E. P., Clark, C. D., Mumby, P. J., Edwards, A. J. and Ellis, A. C., Remote sensing techniques for mangrove mapping. Int. $J$. Remote Sensing, 1999, 19, 935-956.

7. Held, A., Ticehurst, C., Lymburner, L. and Williams, N., High resolution mapping of tropical mangrove ecosystem using hyperspectral and radar remote sensing. Int. J. Remote Sensing, 2003, 24, 2739-2759.

8. Heumann, B. W., Satellite remote sensing of mangrove forests: recent advances and future opportunities. Prog. Phys. Geogr., $2011,35,87-108$

9. Hirano, A., Madden, M. and Welch, R., Hyperspectral image data for mapping wetland vegetation. Wetlands, 2003, 23, 436448.

10. Jensen, R., Mausel, P., Dias, N., Gonser, R., Yang, C., Everitt, J. and Fletcher, R., Spectral analysis of coastal vegetation and land cover using AISA+ hyperspectral data. Geocarto. Int., 2007, 22, $17-28$.

11. Wang, L. and Sousa, W. P., Distinguishing mangrove species with laboratory measurements of hyperspectral leaf reflectance. Int. $J$. Remote Sensing, 2009, 30, 1267-1281.

12. Yang, C., Everitt, J. H., Fletcher, R. S., Jensen, R. R. and Mausel, P. W., Evaluating AISA+ hyperspectral imagery for mapping black mangrove along the South Texas Gulf Coast. Photogramm. Eng. Remote Sensing, 2009, 75, 42.

13. Goetz, A. F. H., Imaging spectrometry for remote sensing: vision to reality in 15 years. In Imaging Spectrometry (eds Descour, M. R. et al.), The International Society for Optical Engineering, Bellingham, WA, USA, 1995, vol. 2480, pp. 2-13.

14. Apan, A. and Phinn, S., Special feature hyperspectral remote sensing. J. Spat. Sci., 2006, 52, 47-48.

15. Kuenzer, C., Bluemel, A., Gebhardt, S., Quoc, T. V. and Dech, S., Remote sensing of mangrove ecosystems: a review. Remote Sensing, 2011, 3, 878-928.

16. Van Der Meer, F., De Jong, S. and Bakker, W., Imaging spectrometry: basic analytical techniques. In Imaging Spectrometry: Basic Principles and Prospective Applications (eds Van Der Meer, F. and De Jong, S.), Kluwer, Dordrecht, The Netherlands, 2001, pp. 17-61.
17. Rohde, W. G. and Olson, C. E., Multispectral sensing of forest tree species. Photogramm. Eng., 1972, 38, 1209-1215.

18. Hestir, E. L., Khanna, S., Andrew, M. E., Santos, M. J., Greenberg, J. A., Rajapakshe, S. S. and Ustin, S. L., Identification of invasive vegetation using hyperspectral remote sensing in the California Delta ecosystem. Remote Sensing Environ., 2008, 112, 4034-4047.

19. Schmidt, K. S. and Skidmore, A. K., Spectral discrimination of vegetation types in a coastal wetland. Remote Sensing Environ., $2003,85,92-108$.

20. Vaiphasa, C. K., Skidmore, A. K., de Boer, W. F. and Vaiphasa, $\mathrm{T}$., A hyperspectral band selector for plant species discrimination. ISPRS J. Photogram. Remote Sensing, 2007, 62, 225-235.

21. Rashmi, S., Addamani, Swapna, Venkat and Ravikiran, S., Spectral mapper algorithm for remote sensing image classification. IJISET - Int. J. Innov. Sci., Eng. Technol., 2014, 1(4), 201-205, ISSN 2348-7968.

22. Demuro, M. and Chisholm, L., Assessment of hyperion for characterizing mangrove communities. In Proceedings of the 12th Earth Science Airborne Workshop, Pasadena, CA, USA, 25-28 February 2003; ftp://popo.jpl.nasa.gov/pub/docs/workshops/03_docs/Demuro_ AVIRIS_2003_web.pdf (accessed on 5 August 2007).

23. Kamal, $\bar{M}$. and Stuart, P., Hyperspectral data for mangrove species mapping: a comparison of pixel-based and object-based approach. Remote Sensing, 2011, 3, 2222-2242; doi:10.3390/rs3102222.

24. Forest Survey of India, State of Forest Report, Government of India, 2013.

25. Szekielda, K. H., Bowles, J. H., Gillis, D. B. and David Miller, W., Interpretation of absorption bands in airborne hyperspectral radiance data. Sensors, 2009, 2907-2925.

26. Kishore, M. and Kulkarni, S. B., Hyperspectral imaging technique for plant leaf identification. In International Conference on Emerging Research in Electronics, Computer Science and Technology, Mandya, Karnataka, India, 2015, pp. 209-213; https:// ieexplore.iee.org/abstract/document/7499014

27. Price, J. C., How unique are spectral signatures? Remote Sensing Environ., 1994, 49, 181-186.

ACKNOWLEDGEMENTS. We thank Shri D. K. Das, Director (Space Applications Centre (ISRO), Ahmedabad) for providing the necessary facilities to carry out this work. We also thank Dr Raj Kumar (Deputy Director, EPSA) for necessary support and suggestions during the campaign; Dr Bimal K. Bhattacharya (Project Director (AVIRIS$\mathrm{NG})$ ) for his continuous involvement throughout the campaign and guidance; the Principal Chief Conservator of Forests of the Odisha and West Bengal Forest Departments, for giving necessary permissions to carry out the ground-truth measurements, and the Forest Departments of Odisha and West Bengal for providing support during field work.

doi: $10.18520 / \mathrm{cs} / \mathrm{v} 116 / \mathrm{i} 7 / 1136-1142$ 